\title{
Atmospheric Properties from the 2006 Niamey Deployment and Climate Simulation with a Geodesic Grid Coupled Climate Model
}

Third Quarter 2008

ARM and Climate Change Prediction Program Report

J. Mather/Pacific Northwest National Laboratory

D. Randall/Colorado State University

C. Flynn/Pacific Northwest National Laboratory

June 2008

Work supported by the U.S. Department of Energy,

Office of Science, Office of Biological and Environmental Research 


\section{DISCLAIMER}

This report was prepared as an account of work sponsored by the U.S. Government. Neither the United States nor any agency thereof, nor any of their employees, makes any warranty, express or implied, or assumes any legal liability or responsibility for the accuracy, completeness, or usefulness of any information, apparatus, product, or process disclosed, or represents that its use would not infringe privately owned rights. Reference herein to any specific commercial product, process, or service by trade name, trademark, manufacturer, or otherwise, does not necessarily constitute or imply its endorsement, recommendation, or favoring by the U.S. Government or any agency thereof. The views and opinions of authors expressed herein do not necessarily state or reflect those of the U.S. Government or any agency thereof. 


\section{Contents}

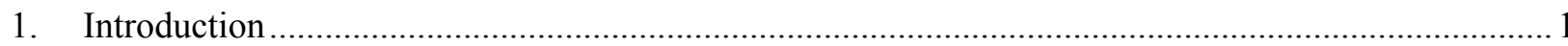

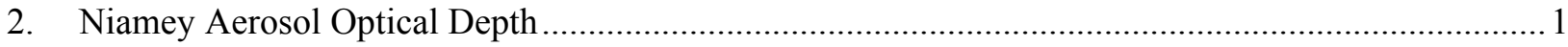

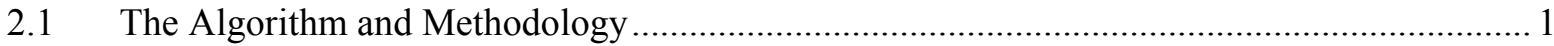

2.2 Impact of High Atmospheric Dust Concentration on AOD Retrievals .................................. 2

2.3 Correcting the MFRSR Aerosol Optical Depth Retrievals ...................................................... 3

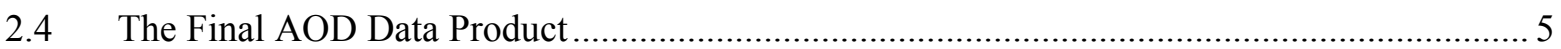

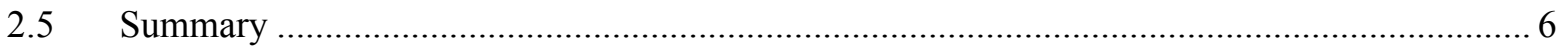

3. A Year-Long Control Simulation Using Geodesic Grid Coupled Climate Model at a Resolution $\sim 250 \mathrm{~km}$, Including a Comparison with Observations ................................................................ 6

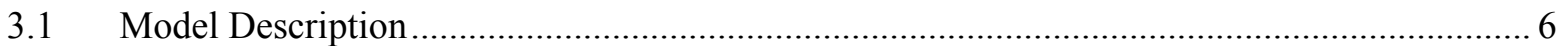

3.2 Initial Testing in Preparation for a Year-Long Control Simulation Using Geodesic Grid

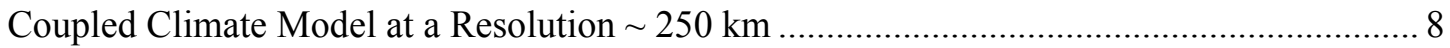

3.2.1 Tests of the Atmosphere and Land-Surface Models with Prescribed Sea-Surface

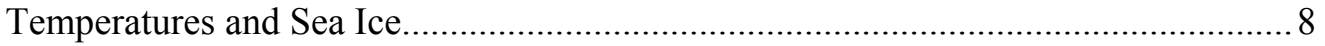

3.2.2 Tests of the Ocean and Sea Ice Models with Prescribed Atmospheric Forcing ........... 9

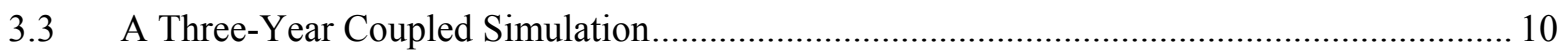

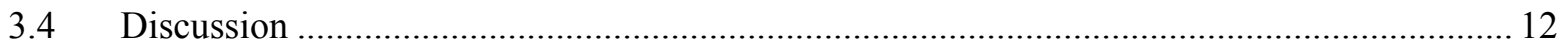

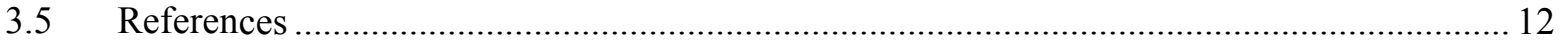

\section{Figures}

1. $\mathrm{I}_{\mathrm{o}}$ values derived from the technique of Michalsky et al........................................................ 2

2. Uncorrected MFRSR AOD plotted versus Cimel AOD, $500 \mathrm{~nm}$................................................. 3

3. Corrected MFRSR AOD plotted versus Cimel AOD, $500 \mathrm{~nm}$................................................ 4

4. Daily averages of corrected $500 \mathrm{~nm}$ AOD and Angstrom exponent ......................................... 5

5. The process used to create a geodesic grid, by starting from an icosahedron............................... 7

6. The observed and simulated annual-mean distributions of total precipitation ............................. 9

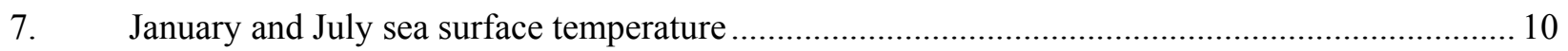

8. Equatorial cross sections of temperature and zonal current, for January of the fourth year of

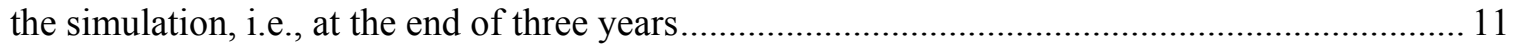

9. The simulated and observed distributions of sea surface height, relative to standard sea level. ... 12 


\section{Introduction}

In 2008, the Atmospheric Radiation Measurement (ARM) Program and the Climate Change Prediction Program (CCPP) have been asked to produce joint science metrics. For CCPP, the metrics will deal with a decade-long control simulation using geodesic grid-coupled climate model. For ARM, the metrics will deal with observations associated with the 2006 deployment of the ARM Mobile Facility (AMF) to Niamey, Niger. Specifically, ARM has been asked to deliver data products for Niamey that describe cloud, aerosol, and dust properties. This report describes the aerosol optical depth (AOD) product.

\section{Niamey Aerosol Optical Depth}

The multi-filter rotating shadowband radiometer (MFRSR) optical depth value-added product (VAP) uses a technique developed by Joseph Michalsky, et al. (2001) as described in the Journal of Geophysical Research, June 2001. This method uses Langley regression data to obtain daily top of atmosphere solar irradiance values (referred to as $\mathrm{I}_{0}$, with units $\mathrm{W} / \mathrm{m}^{2} / \mathrm{nm}$ ) representative of the hypothetical response of the MFRSR in the absence of atmospheric effects. These daily $I_{o}$ values are then used to infer atmospheric transmittance, and thus total optical depth, at five wavelengths from MFRSR data at 15-second temporal resolution. Aerosol optical depths are obtained from the total optical depth through subtraction of pressure-corrected Rayleigh optical depths and ozone optical depths at each wavelength. Although the standard ARM optical depth product uses total ozone mapping experiment spectrometer (TOMS) or ozone monitoring instrument (OMI) satellite data for column ozone amount, a fixed ozone amount of 275 DU was used because Niamey is far from urban and industrial centers.

\subsection{The Algorithm and Methodology}

The method described by Michalsky et al. has been modified to yield optical depth values for each noncloudy time record, rather than a single optical depth for a given day. The basic technique is to obtain many Langley $I_{o}$ values on either side of the day for which the optical depths will be computed. Currently this is approximately 30 days before and 30 days after the date being computed. This set of Langley data then is processed by a modified Forgan technique to remove outliers. The remaining $\mathrm{I}_{\mathrm{o}}$ values then are smoothed using a lowess regression over the entire time range. The smoothed $\mathrm{I}_{\mathrm{o}}$ values for a given day are then used to compute an optical depth for each measurement time. Monitoring the $\mathrm{I}_{\mathrm{o}}$ values in the field allows calibration drifts to be fully accounted for when finding the optical depth.

Figure 1 shows $I_{o}$ values derived using the process described above. These values serve as a field calibration of the MFRSR, and this figure shows that the instrument's calibration is not necessarily steady in time, but may drift considerably. This drift is particularly evident for the 415 and $500 \mathrm{~nm}$ channels during the latter half of the campaign. Because this drift is known, it is correctable, and has no material effect on AOD retrievals. 


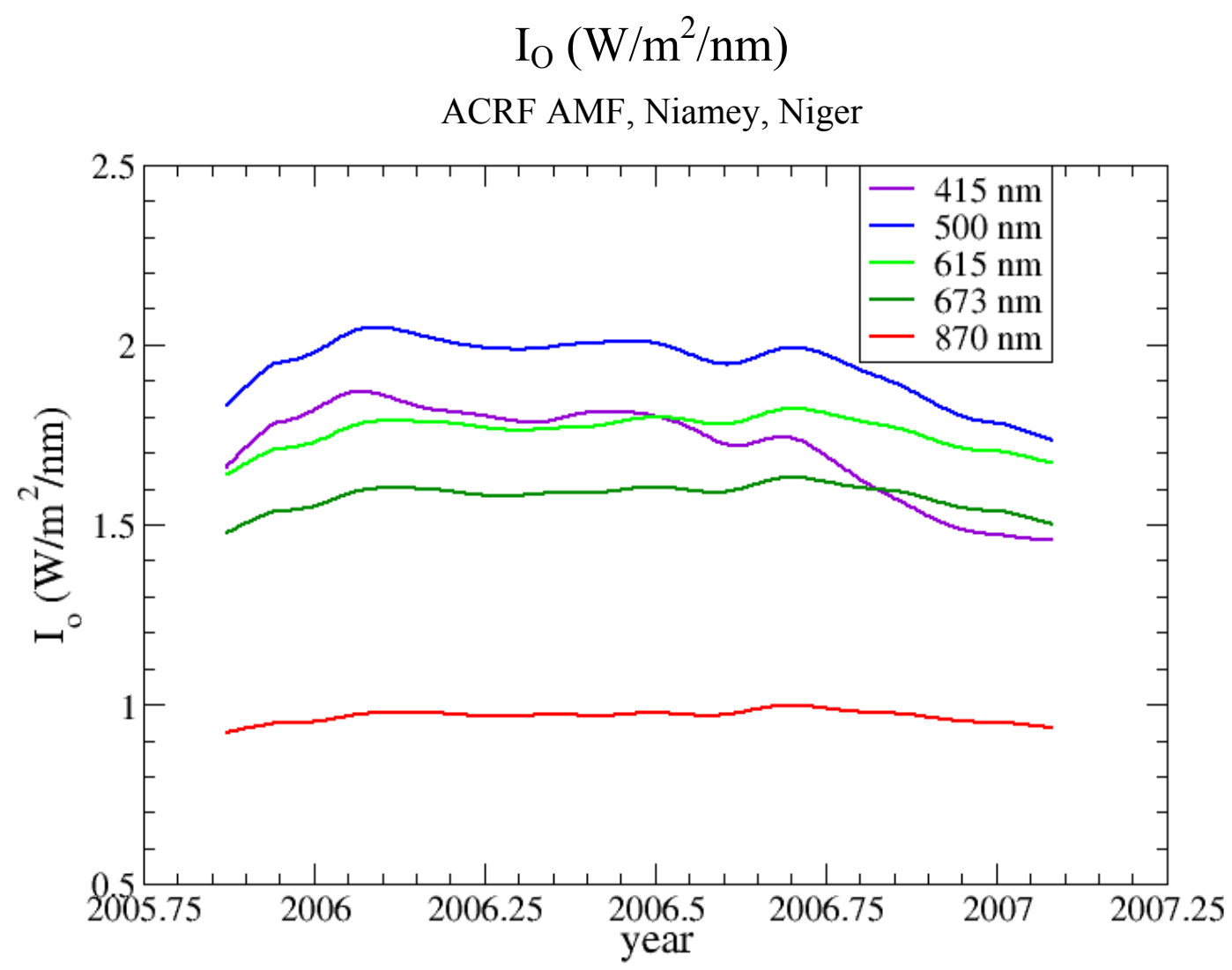

Figure 1: $I_{0}$ values derived from the technique of Michalsky et al. (2000).

\subsection{Impact of High Atmospheric Dust Concentration on AOD Retrievals}

Aerosols in a desert environment, such as the Niamey region, often contain large concentrations of dust. Compared to other types of continental aerosols, dust particles tend to be geometrically large thereby enhancing the forward scattering of radiation when compared to smaller aerosols. This enhanced forward scattering, which can be significant when high numbers of large particles are present, has the potential to contaminate measurements of the direct beam solar irradiance, in turn yielding artificially small computed AOD values.

To assess the extent to which scattering by large particles may be contaminating MFRSR direct beam solar irradiance measurements, we have compared simultaneous determinations of AOD from the MFRSR and a collocated Cimel sun photometer (data available through Aeronet http://aeronet.gsfc.nasa.gov/). The Cimel sun photometer was available from August 5, 2006, onwards and therefore only covers part of the AMF deployment in Niamey from November 2005 through January 2007.

The effect of field-of-view (FOV) issues on AOD measurements in general, and for the Cimel sun photometer in particular, has been discussed by Russell et al. and references therein (2004). Russell et al.'s calculations suggest that given the Cimel's half-angle FOV of 1.2 degrees, the effects of forward 
scattering will be negligible for that instrument. The shadowband technique used by the MFRSR does not readily lend itself to standard definitions of FOV, so the treatment outlined by these authors is not immediately applicable. However, Monte-Carlo simulations of the MFRSR measurement assuming Mie scattering suggest the need for corrections to MFRSR-derived AOD of several percent. Significantly though, the magnitude of the forward scattered light may be even more prominent than for this Mie scattering approximation, as noted by Russell et al, when jagged or non-spherical dust comprises a significant fraction of the aerosol present, such as for certain times of the year in Niamey.

To what extent do the observed AODs differ between the MFRSR and Cimel? Figure 2 shows a scatter plot of Cimel AOD plotted versus MFRSR AOD (500 nm). The thick black line is the 1:1 line. Although the MFRSR and Cimel AODs are well correlated, the MFRSR AODs are consistently lower (about 15\%) than the corresponding Cimel AODs. This result is in contrast to previous comparisons conducted at the ARM Climate Research Facility (ACRF) Southern Great Plains (SGP) site which routinely show excellent agreement. This suggests that in the dusty environment of Niamey, MFRSR AODs require correction because of forward scattering.

\section{Uncorrected MFRSR vs Cimel AOD (500nm)}

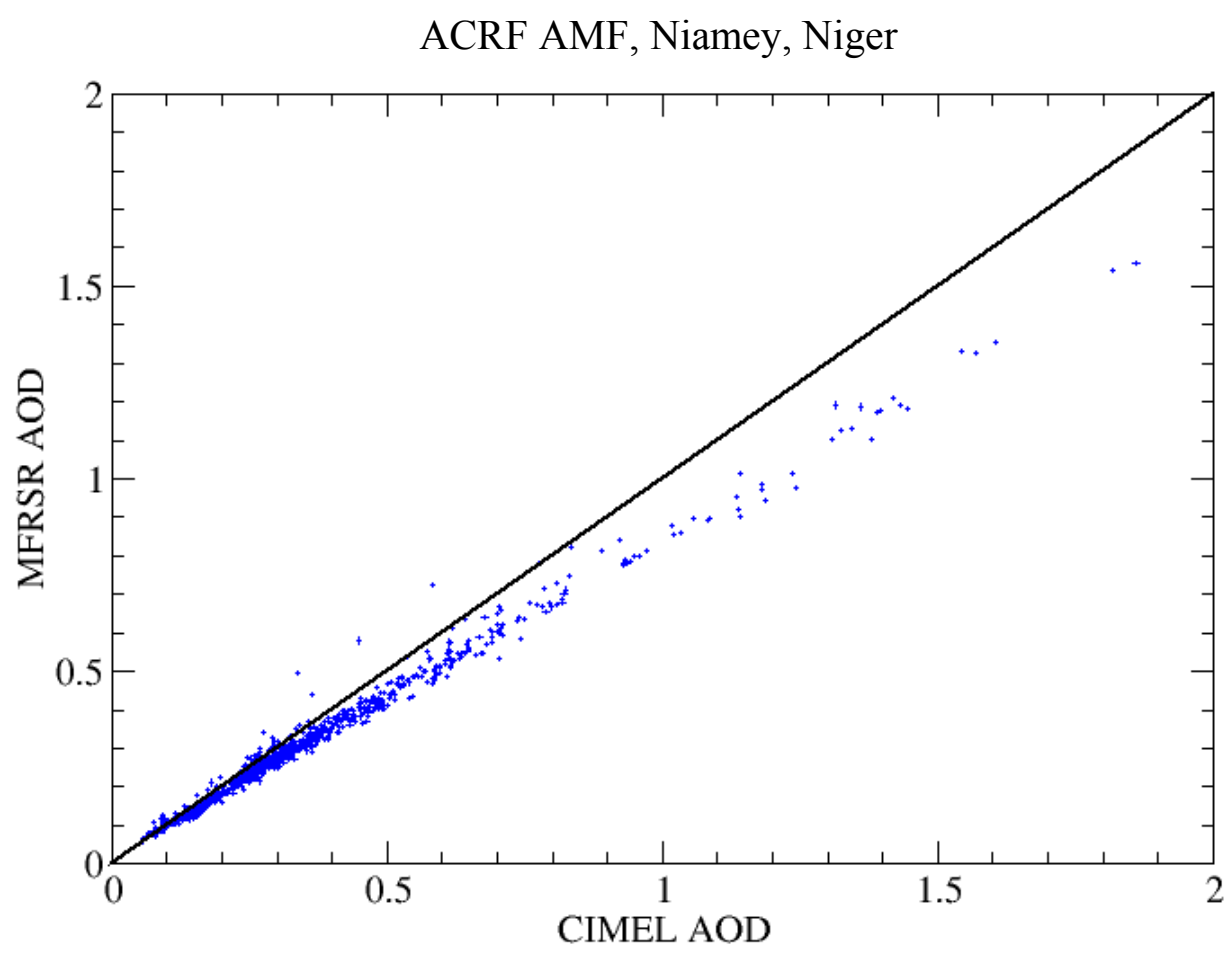

Figure 2: Uncorrected MFRSR AOD plotted versus Cimel AOD, $500 \mathrm{~nm}$.

\subsection{Correcting the MFRSR Aerosol Optical Depth Retrievals}

We assume that the entire difference in AODs between the two instruments is caused by excess forward scattering into the MFRSR direct beam solar irradiance measurement, and concomitantly, that the Cimel measurements represent "truth." To correct the MFRSR AODs, we devise a scheme similar to that 
presented in Russell et al. (2004), for which the correction depends on the Angstrom exponent as a proxy for the aerosol size. For large Angstrom exponents (smaller particles), the correction is small, and the magnitude of the correction increases as the Angstrom exponent decreases (larger particles).

Multiplicative correction coefficients, $a(\lambda)$, were derived so that the corrected AOD is given by $($ Corrected AOD $)=($ Uncorrected AOD $) * a(\lambda)$. Note that the correction depends on the wavelength, and is largest for the smallest wavelength, consistent with forward scattering contamination. When finding the correction coefficients, it was observed that the overall correction was improved significantly by using two sets of coefficients: one set applicable for data collected from December through February, and the other one for data collected outside these months. December 1 corresponds strikingly to the start of the Harmattan wind, a northeast wind that blows from the Sahara over the Niamey. Because of this close correspondence, we speculate that the Harmattan advects aerosols with different properties over the Niamey site than are present during other parts of the year, when the wind is from elsewhere. It therefore seems reasonable that two correction coefficients are necessary.

Because the Cimel did not collect irradiance data at $415 \mathrm{~nm}$, finding a correction coefficient for this wavelength was not possible with the previous scheme, so we instead calculated a corrected MFRSR AOD at $415 \mathrm{~nm}$ by extrapolating the corrected $500 \mathrm{~nm}$ AOD to $415 \mathrm{~nm}$ using the Angstrom exponent relationship. The corrected MFRSR AODs are shown in Figure 3, in which is seen that the correction works quite well. With this result as validation during the limited period for which both the MFRSR and the Cimel are present, we proceed to correct the MFRSR product for the entire deployment period including when the Cimel was not available.

\section{Corrected MFRSR vs Cimel AOD (500nm)}

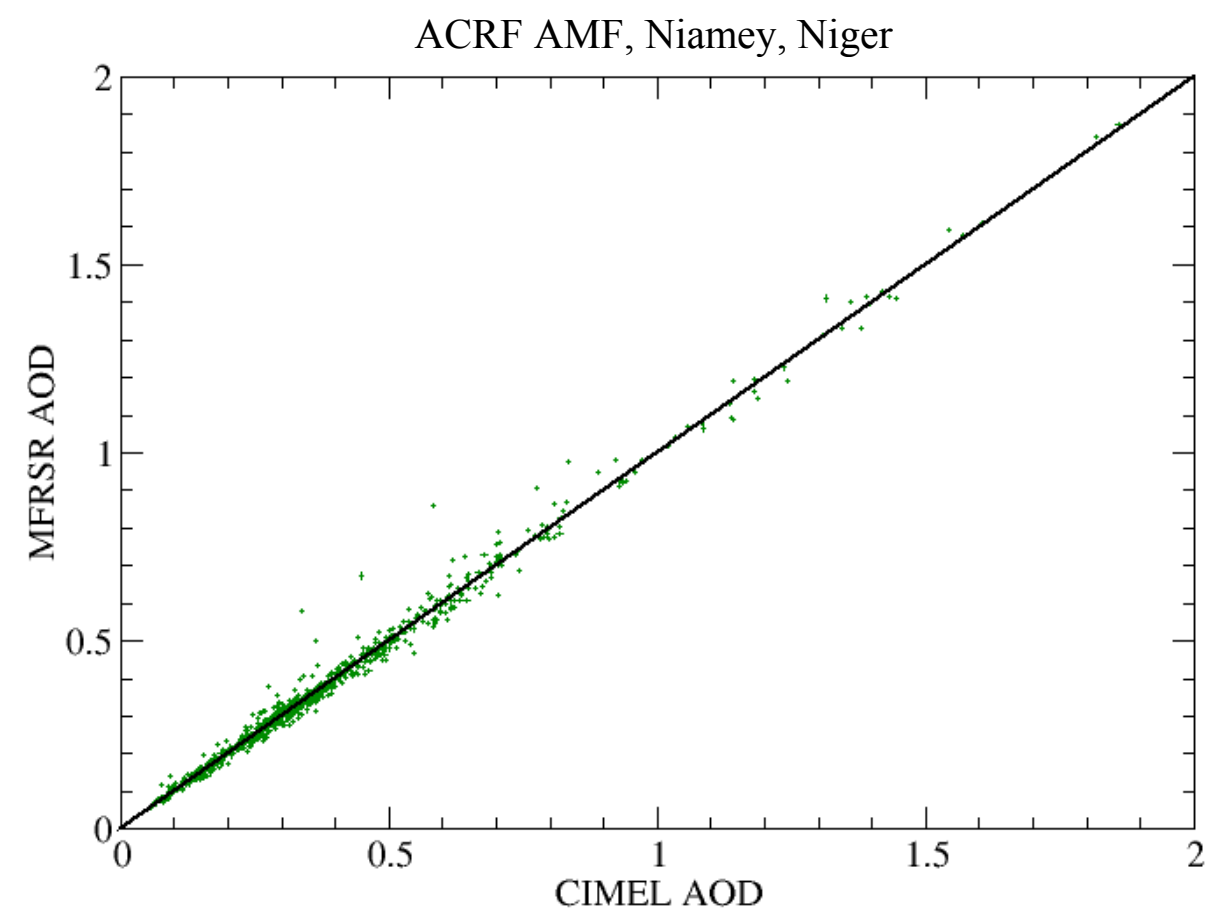

Figure 3: Corrected MFRSR AOD plotted versus Cimel AOD, $500 \mathrm{~nm}$. 


\subsection{The Final AOD Data Product}

Two types of data files are provided: a detailed file and a summary file containing daily averages. The detailed data file contains the aerosol optical depths for each cloud-screened MFRSR sample at wavelengths of $415 \mathrm{~nm}, 500 \mathrm{~nm}, 615 \mathrm{~nm}, 673 \mathrm{~nm}$, and $870 \mathrm{~nm}$, and an Angstrom exponent derived from the $500 \mathrm{~nm}$ and $870 \mathrm{~nm}$ channels. The detailed file also includes the multiplicative forward scattering corrections $\mathrm{a}(\lambda)$ that were applied to yield these final AOD values. The detailed file is available as ASCII and netcdf format.

The summary file, in ASCII only, contains daily averaged aerosol optical depths for the same five wavelengths and a daily averaged angstrom exponent. This data set, as plotted in the upper panel of Figure 4, illustrates the variation in AOD over the course of the Niamey campaign. The Angstrom exponent is also plotted in the lower panel.

\section{Daily Averaged AOT (500 nm) and Angstrom Exponent}
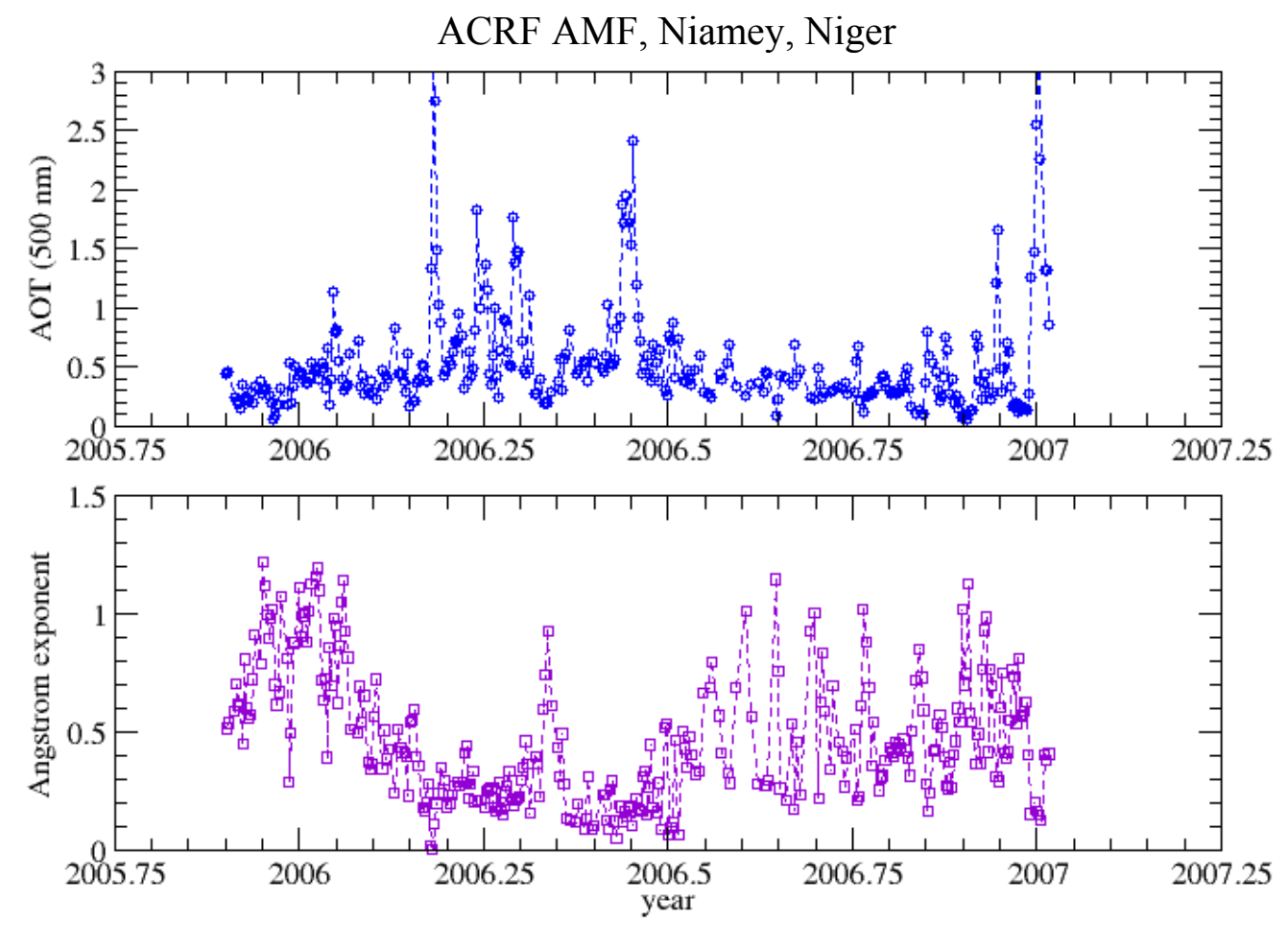

Figure 4: Daily averages of corrected $500 \mathrm{~nm}$ AOD and Angstrom exponent. The Angstrom exponent is calculated from the corrected MFRSR AODs at 500 and $870 \mathrm{~nm}$.

This figure illustrates several interesting aspects of the AOD climatology during the year. The Angstrom exponent tends to be large during the "cool", dry season, extending from December through February. This is probably a result of the Harmattan wind blowing aerosols of smaller sizes over Niamey than are present during other parts of the year. Additionally, for a few selected times, the AOD can become very large ( $>2$ ), with correspondingly small Angstrom exponents. Some of these times are indicative of very high dust loadings, appropriately described as dust storms. For example, a dust storm that swept over the 
area in early March (March $7-11$ ) is represented by the spike of AOD that occurs around 2006.23. Slingo et al. (2007) used these MFRSR data, and data taken from other instruments, including those borne on satellite, to estimate the columnar shortwave and longwave radiation budgets during dust storm conditions. In this regard, the ACRF deployment provided very unique data, without which this study could not have been executed.

\subsection{Summary}

MFRSR irradiance data collected during the ACRF AMF deployment in Niamey, Niger, have been used to derive AOD for five wavelength channels of the MFRSR. The AOD data extend from November 2005 through January 2007. Because the atmosphere around Niamey often contains a large dust burden, and because these dust particles are large, significant forward scattering occurs that contaminates the MFRSR's inference of the direct beam irradiance. This contamination, in turn, causes AODs obtained from the MFRSR direct beam to be too small. That such contamination is indeed occurring is substantiated by comparing MFRSR AODs with the same obtained from the Cimel sun photometer. The narrow FOV of the Cimel essentially eliminates the forward scattering problem and AODs derived from this instrument can be considered as "uncontaminated" by forward scattering.

A scatter plot of AODs from the two instruments shows that the MFRSR AOD is indeed lower than the Cimel AOD by a substantial amount (10-15\%), suggesting that the forward scattering discussed above is an important factor. The MFRSR AODs were corrected to match the Cimel AODs following a method similar to that described in Russell et al. (2004). This allows the construction of a corrected data set that extends throughout the AMF deployment period, rather than just the limited time period when the Cimel was operational.

An examination of the daily averaged AODs at $500 \mathrm{~nm}$ reveals several interesting features. The first of these is the presence of very large AODs $(\geq 2)$, of several days duration. Such spikes occurred several times during the year-long campaign. One of these cases occurred in early March, and is indicative of an intense dust storm, which was intensely studied by ARM research (Slingo et al., 2006). The time series of Angstrom exponent indicates that the exponent exhibits seasonable variability, being largest during December through February and smallest during the second quarter of the year, April through June.

\section{A Year-Long Control Simulation Using Geodesic Grid Coupled Climate Model at a Resolution $\sim 250 \mathrm{~km}$, Including a Comparison with Observations}

\subsection{Model Description}

The Coupled Colorado State Model (CCoSM) is a climate model in which each component is discretized on a geodesic grid (Figure 5). A geodesic grid consists of hexagons and pentagons. The grid-cells are relatively uniform across the globe, varying in area by only $5 \%$, and the grid is quasi-isotropic. The distinct climate components in CCoSM are the atmosphere, ocean and sea ice, and their coupling is coordinated by a coupler component which computes the interfacial fluxes and PBL physics. 


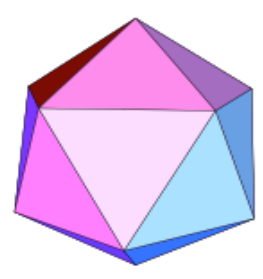

Icosahedron

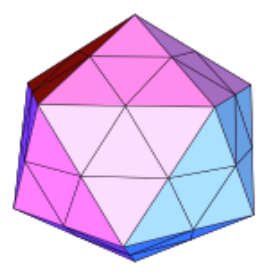

Bisect each edge and connect the dots

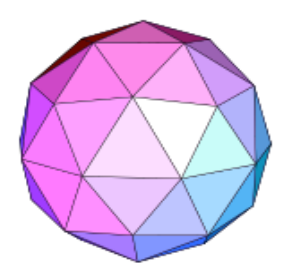

Pop out onto the unit sphere
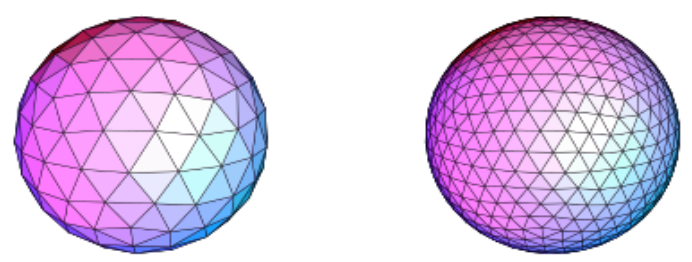

And so on, until we reach our target resolution...

Figure 5: The process used to create a geodesic grid, by starting from an icosahedron.

The geodesic grid can be decomposed into logically rectangular subdomains, which are used to do memory allocation on a computer. Each subdomain can be decomposed in two dimensions. The model runs in a multiple-processor environment using the message passing interface (MPI).

The atmosphere sub-model includes prognostic equations for potential temperature, vorticity and divergence, surface pressure, specific humidity, cumulus kinetic energy (CKE), mixing ratios of cloud water, cloud ice, rain and snow, and the planetary boundary layer (PBL) depth. The discretization of the advection is highly conservative. The vertical coordinate is a generalized sigma coordinate, in which the PBL top is a coordinate surface. There are 29 layers, with the model top at $1 \mathrm{mb}$.

Deep moist convection is parameterized using a modified Arakawa-Schubert scheme with ice, prognostic CKE, cumulus friction, and multiple cloud bases (Pan and Randall, 1998; Ding and Randall, 1998). The large-scale cloud microphysical scheme is the one developed by Fowler et al. (2006), with cumulus detrainment as a source of cloud water and/or ice. The radiation is the Stephens parameterization. Gravity-wave drag is parameterized with a simple Palmer-like scheme (Palmer et al., 1986). Further details are given by Ringler et al. (2000) and Randall et al. (2002).

The ocean sub-model has prognostic equations for momentum, temperature, salinity and the free surface height. Depth is used as the vertical coordinate, with 33 layers. Horizontal transport is done by monotone flux-corrected transport, and vertical transport by monotone remapping. KPP (Large et al., 1994 ) is used to parameterize the ocean boundary-layer turbulence and convection.

The sea ice sub-model predicts ice concentration, volume and energy content. There are four ice layers, and snow is accumulated on the ice. The dynamics are based on the elastic-viscous-plastic rheology (Hunke and Dukowicz, 1997). The thermodynamics are based on Semtner (1976). Flux-corrected transport is used to advect the ice. 
In addition, CCoSM includes a sub-model for land-surface processes, SiB2, which was developed by Sellers et al. (1996). SiB2 includes parameterizations of canopy physiological responses (photosynthesis, stomatal conductance), and was designed to utilize satellite measurements for many of the important vegetation boundary conditions such as fraction of short wave radiation absorbed, leaf area index, albedo and roughness.

The integrations of the these several components are coordinated by a software component called a coupler. On every time step, variables needed to compute the fluxes of mass, momentum and energy between components are passed to the coupler. The coupler computes these fluxes and sends them to the components. To deal with possible differences in resolution, a conservative interpolation is performed using SCRIP, which was developed at the Los Alamos National Laboratory (Jones, 1999). The PBL parameterization, which determines the surface fluxes, PBL-top entrainment rate, and PBL-cloudiness, is implemented in the coupler.

The coupler can also be used to replace climate components with prescribed data. For instance, the dynamic ocean and sea ice modules can be replaced with prescribed sea surface temperature and ice cover to drive the atmosphere; the dynamic atmosphere can be replaced with prescribed surface air conditions, radiative fluxes and precipitation to drive the ocean. In the tests described below, the coupler was used in this way.

\subsection{Initial Testing in Preparation for a Year-Long Control Simulation Using Geodesic Grid Coupled Climate Model at a Resolution 250 km}

\subsubsection{Tests of the Atmosphere and Land-Surface Models with Prescribed Sea-Surface Temperatures and Sea Ice}

The atmosphere and land-surface models have been subjected to many tests over a period of years. In a particularly important test, we have performed an "AMIP" simulation (the acronym stands for “Atmospheric Model Intercomparison Project;" Gates, 1992), in which observed sea-surface temperatures and sea-ice distributions for the years 1979-1988 were prescribed as input. The model results are then analyzed to see if the simulated atmosphere and land surface respond to the year-to-year variations in the sea-surface temperature and sea ice in the same way as observed in the real world. We used $250 \mathrm{~km}$ grid spacing. An example of the results from our AMIP run is shown in Figure 6, which compares simulated and observed annual-mean total precipitation.

To test the ocean and sea-ice models, we have performed simulations in which the ocean and sea ice are "forced" with prescribed atmospheric data. The initial conditions for the ocean are rest (no currents), with temperature and salinity from the Levitus (1982) January climatology. The sea ice is initialized with a realistic January 1 distribution of $95 \%(90 \%)$ concentration for the northern (southern) hemisphere, with a thickness of $2 \mathrm{~m}(1 \mathrm{~m}), 0.2 \mathrm{~m}$ of snow cover, and an ice-surface temperature of $-1{ }^{\circ} \mathrm{C}$, and interior ice snow energies consistent with temperatures of $0{ }^{\circ} \mathrm{C}$. The atmospheric driving data are from the ERA-40 reanalysis (Uppala et al., 1999), interpolated to the geodesic grid. The model was integrated for four years with a $200 \mathrm{~s}$ time step for all components. We used $250 \mathrm{~km}$ grid-spacing. 


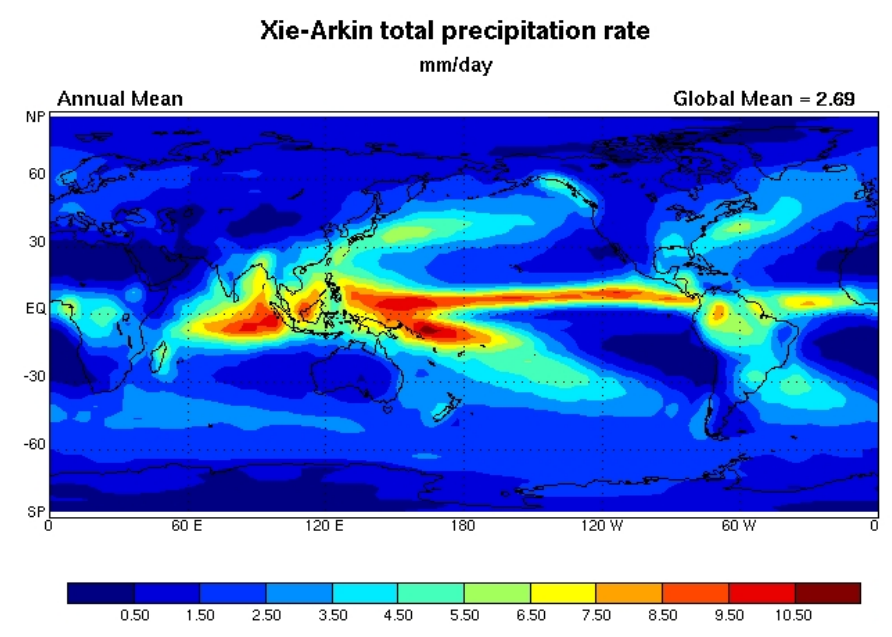

TOTAL PRECIPITATION RATE

mmiday

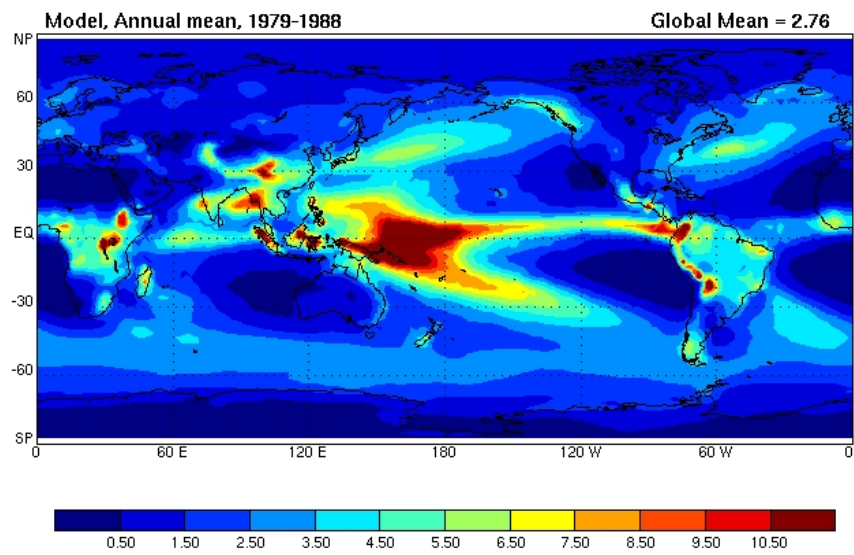

Figure 6: The observed (top panel) and simulated (bottom panel) annual-mean distributions of total precipitation. The simulation is based on an AMIP run, as described in the text.

\subsubsection{Tests of the Ocean and Sea Ice Models with Prescribed Atmospheric Forcing}

Figure 7 shows the mean January and July sea surface temperature maps from the National Oceanic and Atmospheric Administration (NOAA) data (1971 - 2000 mean), and the simulation (four-year mean). The tropical patterns are well reproduced, cold in the eastern part of the basins and warmer in the west, but the cold bias in the tropics is evident. Analysis shows that the simulated cooling is associated with an excessive deepening of the tropical mixed layer. 

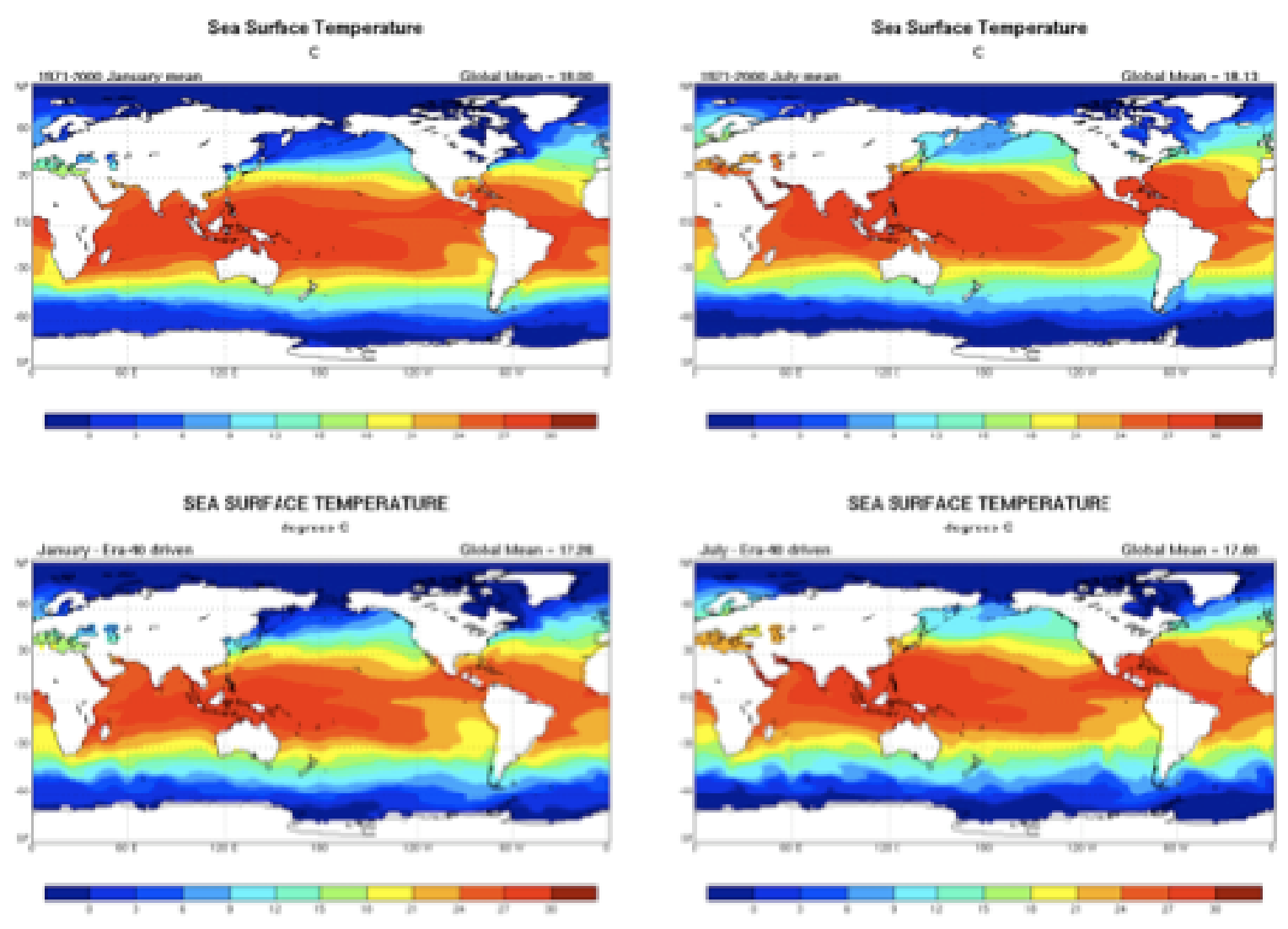

Figure 7: January (left column) and July (right column) sea surface temperature. At the top is the 19712000 mean from NOAA, and the lower two plots show the four-year mean from the data-driven ocean and sea-ice models.

The tests described above set the stage for the coupled simulation described in the next section.

\subsection{A Three-Year Coupled Simulation}

In our coupled simulation, the atmosphere was initialized using January 1 restart record from an earlier long run in which the atmosphere model was driven using observed sea-surface temperatures, as described in Section 3.2 above. Similarly, the ocean model was initialized using a January 1 restart from an earlier run in which it had driven with ERA-40 re-analysis data (Upalla et al., 1999), as described in Section 3.2 above.

Equatorial cross-sections of the temperature and zonal current are shown in Figure 8. The simulated thermocline depth and Equatorial Undercurrent rise towards the surface, from west to east across both the Pacific and Atlantic basins, in agreement with observations. The east-west surface temperature gradients and thermocline depths are realistic. 
Temperature

c
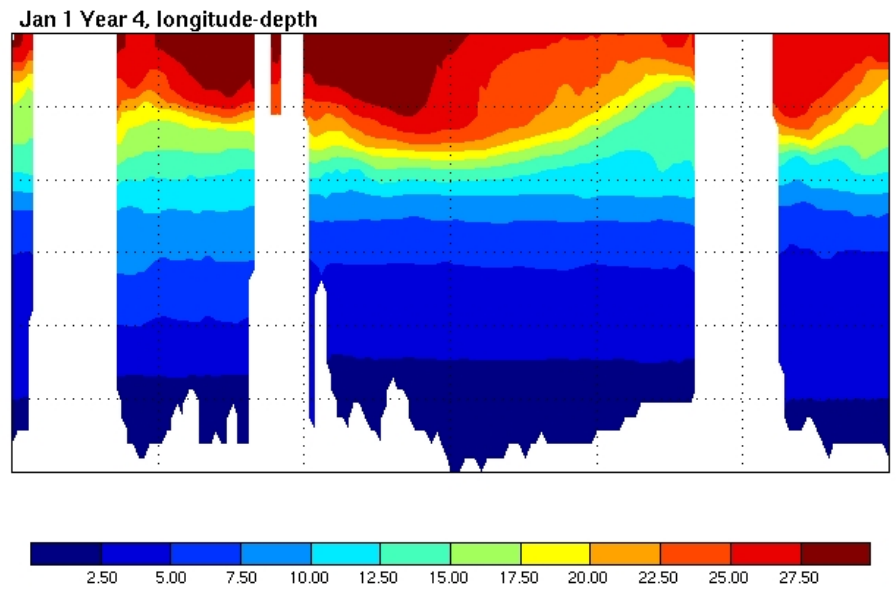

Zonal Current

$\mathrm{m} / \mathrm{s}$

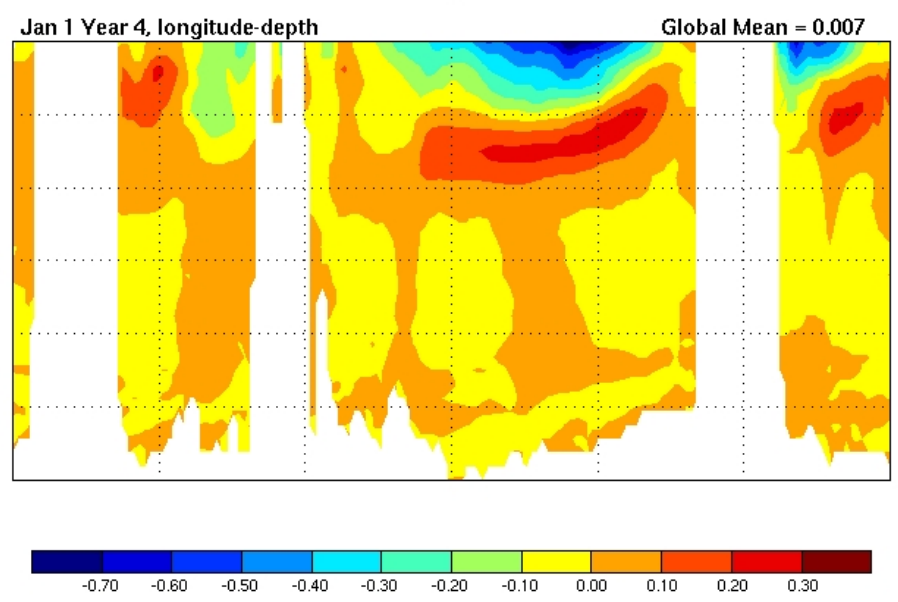

Figure 8: Equatorial cross sections of temperature and zonal current, for January of the fourth year of the simulation, i.e., at the end of three years. The right and left boundaries of the plots are at the Greenwich meridian. The white "vertical stripes" are land masses. The Pacific is slightly to the right of center. The thermocline depth and Equatorial Undercurrent can be seen rising from west to east across both the Pacific and Atlantic, in agreement with observations.

Figure 9 shows the simulated and observed distributions of sea surface height, relative to standard sealevel. The model does a good job of simulating the observed patterns. 


\section{SEA SURFACE HEIGHT RELATIVE TO SEA LEVEL}

meters
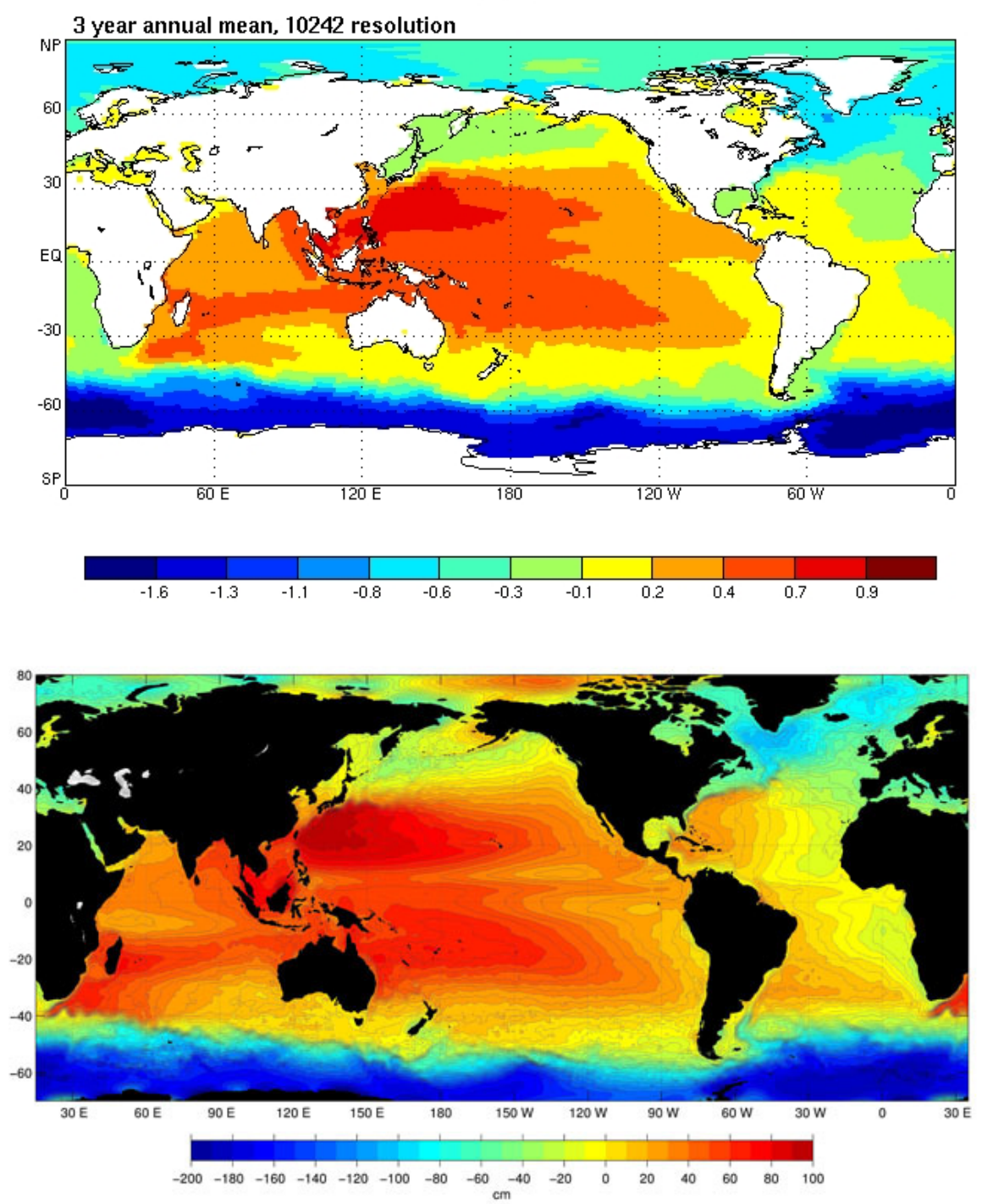

Figure 9: The simulated (top) and observed (bottom) distributions of sea surface height, relative to standard sea level.

\subsection{Discussion}

We are now preparing a decadal simulation with the coupled model.

\subsection{References}

Ding, P, and DA Randall. 1998. "A cumulus parameterization with multiple cloud base levels." $J$. Geophys. Res. 103, 11341-11354. 
Fowler, LD, DA Randall, and SA Rutledge. 1996. "Liquid and ice cloud microphysics in the CSU general circulation model. part 1: model description and simulated microphysical processes." J. Climate. 9, 489-529.

Gates, WL. 1992. "AMIP: The atmospheric model intercomparison project.” Bull. Amer. Meteor. Soc., 73, 1962 - 1970.

Heikes, RP, and DA Randall. 1995. "Numerical integration of the shallow water equations on a twisted icosahedral grid. Part I: Basic design and results of tests.” Mon. Wea. Rev. 123, 1862-1880.

Hunke, EC, and JK Dukowicz. 1997. "An elastic-viscous-plastic model for sea ice dynamics." J. Phys. Oceanogr. 27, 1849-1867.

Jones, PW. 1999. "First- and second-order conservative remapping schemes for grids in spherical coordinates." Mon. Wea. Rev. 127, 2204-2210.

Large, WG, JC McWilliams, and SC Doney. 1994. "Oceanic vertical mixing: a review and a model with a nonlocal boundary layer parameterization." Rev. Geophys. 32, 363-403.

Levitus, S. 1982. "Climatological atlas of the world oceans." NOAA Prof. Paper 13, U. S. Govt. Printing Office, Washington, D.C.

Michalsky, JJ , JA Schlemmer, WE Berkheiser, JL Berndt, LC Harrison, NS Laulainen, NR Larson, and JC Barnard. 2001. "Multiyear measurements of aerosol optical depth in the Atmospheric Radiation Measurement and Quantitative Links Programs." J. Geophys. Res. 106: 12,099.

Palmer, TN, GJ Shutts, and R Swinbank. 1986. "Alleviation of a systematic westerly bias in general circulation and numerical weather prediction models through an orographic gravity wave drag parametrization." Quart. J. R. Met. Soc. 112, 1001-1039.

Pan, D-M, and DA Randall. 1998. "A cumulus parameterization with a prognostic closure." Quart. J. Roy. Met. Soc. 124, 949-981.

Randall, DA, TD Ringler, RP Heikes, P Jones, and J Baumgardner. 2002. "Climate modeling with spherical geodesic grids." Computing in Science Engr. 4, 32-41.

Reynolds, RW, and TM Smith. 1995. "A high resolution global sea surface temperature climatology.” $J$. Climate. 8, 1571-1583.

Ringler, TD, RP Heikes, and DA Randall. 2000. "Modeling the atmospheric general circulation using a spherical geodesic grid: A new class of dynamical cores." Mon. Wea. Rev. 128, 2471-2490.

Russell, PB, JM Livingston, O Dubovik, SA Ramirez, J Wang, J Redemann, B Schmid, M Box and BN Holben. 2004. "Sunlight transmission through desert dust and marine aerosols: Diffuse light corrections to Sun photometry and pyrheliometery." J. Geophys. Res., 109, D08207, doi:10.1029/2003JD004292. 
Sellers, PJ, DA Randall, GJ Collatz, J Berry, C Field, DA Dazlich, C Zhang, and L Bounoua. 1996. “A revised land-surface parameterization (SiB2) for atmospheric GCMs. part 1: model formulation." $J$. Climate. 9, 676-705.

Semtner, AJ Jr. 1976. "A Model for the thermodynamic growth of sea ice in numerical investigations of climate.” J. Phys. Oceanogr. 6, 379-389.

Slingo. A, TP Ackerman, RP Allan, EI Kassianov, SA McFarlane, GJ Robinson, JC Barnard, M Miller, JE Harries, JE Russell, and S. Dewitte. 2006. "Observations of the impact of a major Saharan dust storm on the atmospheric radiation budget." Geophysical Research Letters, 33, L24817, doi:10.1029/2006GL027869.

Stephens, GL, PM Gabriel, and PT Partain. 2001. "Parameterization of atmospheric radiative transfer. Part I: validity of simple models.” J. Atmos. Sci. 58, 3391 - 3409.

Uppala, S, JK Gibson, M Fiorino, A Hernandez, P Kållberg, X Li, K Onogi, and S Saarinen. 1999. "ECMWF second generation reanalysis_ERA40." Proc. Second WCRP Int. Conf. on Reanalyses, Wokefield Park, United Kingdom, WCRP. 9-13. 